\title{
Complementary Therapy as an Approach in Managing Occupational Stress
}

\author{
Nur Aishah Nor Hashim ${ }^{1}$ \\ Florianna Lendai ak Michael Mulok ${ }^{2 *}$ \\ Helmi Sumilan ${ }^{3}$
}

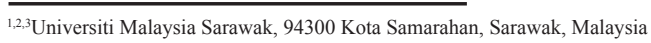

\begin{abstract}
Occupational stress is caused by various reasons, such as, workload and long working hours. This leads to occurrence of trend in using wellness activities to treat physical and psychological illness that is known as complementary therapy, which is Yoga, Aromatherapy, Qi gong, and Islamic Medical Practices (Ruqyah). Therefore, this research offered a perspective on the use of complementary therapies as a tool in improving and maintaining mental health condition of employees located in Penang, Malaysia. Qualitative method was used where 5 complementary therapy practitioners were interviewed to identify the perceptions towards the use of complementary therapy and to identify the type of therapy that can be practiced to reduce stress, as well as, discuss the benefits of complementary therapies. It was found that complementary therapy is very beneficial as it acts as a holistic treatment, natural way of healing and more empowering, as it helps to improve employee's mental, emotional and physical health.
\end{abstract}

Keywords: occupational stress; complementary therapy; mental health; holistic; conventional

\section{INTRODUCTION}

Occupational stress is caused by various types of stressors, such as, workload, long working hours, role ambiguity and role conflict experienced by employees leading to

\section{ARTICLE INFO}

E-mail address:

mmflendai@unimas.my (Florianna Lendai ak Michael

Mulok)

*Corresponding author

ISSN: 2462-1153

(C) Faculty of Cognitive Sciences and Human Development, Universiti Malaysia Sarawak (UNIMAS) depression, anxiety, work-related stress, burnout and absenteeism (Johnson, Cooper, Cartwright, Donald, Taylor, \& Millet, 2005). Complementary therapy is a type of treatment that can also be described as a non-conventional medicine. It serves as an alternative approach to mental healthcare that emphasizes on the interrelationship between mind, body and spirit. The commonly used complementary therapies are music therapy, relaxation technique, acupuncture, mindfulness meditation, 
aromatherapy, massage, yoga, Tai chi, Qi gong and massage therapy. World Health Organization (2005) announced that 450 million people are suffering from mental related disorder, and 815000 people out of 10 to 20 million committed suicide each year with one of the contributing factors of mental related disorder that is occupational stress. However, a study conducted in Malaysia found that employees are stressed due to high workloads (Manshor, Fontaine, $\&$ Chong, 2003). Several approaches have been initiated at the workplace in improving the mental health of employees as suggested by European Agency for Safety and Health at Work (2014), such as, stress management training, health circles and free counseling session for employees. Another case study was conducted by European Agency for Safety and Health at Work (2014) on innovative approaches to mental health promotion at workplace including "The story-telling approach", health-related individual interview, and financial support for employees who are facing crisis. However, there is no known study that has explored the use of complementary therapy at the workplace as an approach in maintaining, and improving the mental health of employees. Abuduli, Ezat, and Aljunid (2011) mentioned that complementary therapy was proven to be able to help in mental health disorders, such as, insomnia, anxiety and depression, and has been suggested to be applied in $75 \%$ of chronic illness and $99 \%$ for psychiatric illness in Shenyang, China. The growing interest towards complementary therapy is the result of awareness and crucial role of psychological distress (Park, 2013). Despite the use of complementary therapy practices by health practitioner in the field of psychology, there is no known study that has specifically looked into the effects of complementary practices towards occupational stress. Therefore, this study offered a perspective on the use of complementary therapy as a tool in improving and maintaining mental health, specifically at workplace, and identifying Malaysian employees' perception in regard to the use of complementary therapy, as well as, to identify the type of therapy that can be practiced to reduce stress.

The research questions are as follows:

i. What are the perceptions toward the use of complementary therapies?

ii. What are the types of complementary therapies practiced by employees to reduce stress?

iii. What are the effects of complementary therapies on occupational stress?

The objectives of the research are as follows:

i. To study the perceptions towards the use of complementary therapies.

ii. To identify the complementary therapies that can be practiced by employees to reduce stress.

iii. To discover the effects of complementary therapies on occupational stress.

This exploratory research seeks to discover insights and ideas regarding complementary therapy as all approach in handling occupational stress issue in the workplace.

\section{LITERATURE REVIEW}

\section{Occupational Stress}

Occupational stress is when environmental condition creates a physical or emotional demand that seeks for adaptive response by the employee (Choi, Tan, Teoh, \& Muthuveloo, 2014). Jamal (2011) empha- 
Nur Aishah Nor Hashim, Floriana Lendai ak Michael Mulok, and Helmi Sumilan

sized that job stress is caused by extreme aversive nature to employee that creates a lethal work environment which forces employees to use an amount of time and energy to cope with the situation. Occupational stress arises from the interactions of several factors that are the type of work, work stressors, degree of support, and coping mechanism (Johnson, Cooper, Cartwright, Donald, Taylor, \& Millet, 2005). Thus, results experienced by an employee due to a series of work demands will lead to a series of outcomes concerning health, such as, illness, injury or behavioral changes (Moustaka \& Constantinidis, 2010). In Malaysia, occupational stress issue is critical. This is due to the social and economic forces that have impacted the work environment of Malaysian and created new career challenges (Idris, Dollard, $\&$ Winefield, 2010). A study conducted by Regus (2013) among business owners and senior executives showed that $48 \%$ of the Malaysian respondents had experienced a rise in stress levels, and $42 \%$ of the respondents claimed that they have less sleeping hours due to work worries. Another study found that there is a correlation between gender, academic rank, and employment status with job stress in Malaysia (Safaria, Ahmad, \& Wahab, 2008).

\section{Complementary therapy}

Complementary therapy is a diverse health practice that governs the uses of plant, animal, mineral based, spiritual therapies, manual techniques and exercises to prevent illness or maintain well-being (Raja, Oranye, Ho, Zuraida, \& Zulkifli, 2013). National Centre for Complementary and Alternative Medicine (2009) has recognized sixteen types of complementary therapies which are acupuncture, biofeedback, hypnosis, homeopathy, energy healing, imagery, spiritual healing, chiropractic, mas- sage, herbal medicine and relaxation techniques. On the other hand, Ching, Paimin, and Jalalian, (2013) classified complementary therapy into five categories of biological based, energy therapies, manipulative, body based, and mind body intervention. Meanwhile, Ministry of Health Malaysia (2011) divided complementary therapy into two concepts; a) healing or treating illness, and b) wellness referring to sustainability of health. Merican (2002) suggested that complementary medicine in Malaysia has a convergence of three Asian cultures, which are Malay, Chinese and Indian and are usually referred as traditional practices. The Traditional and Complementary Medicine Division of Ministry of Health Malaysia (2014) subdivided them into traditional Chinese practice, traditional Indian practice, Islamic medical practice, traditional Malay practice, Homeopathy medicine, Manipulative based medicine, and mindbody soul practice, biological based and energy based therapy. In Malaysia, massage is one of the manipulative based practices. According to the Traditional and Complementary Medicine Division of Ministry of Health Malaysia (2014), massage is often associated with the use of essential oils. Aromatherapy involved the use of essential and aromatic oil and commonly used for therapeutic massage to reduce anxiety and enhance relaxation.

There are several activities according to the traditional Indian practice that are yoga, Ayurveda, Siddha and Unani. Milligan (2006) found that yoga is an affective stress management program to enhance relaxation skills, improve focus attention, reduce anxiety, reduce depression and improve overall wellness. Another similar study conducted by Deshpande (2012) claimed that yoga, meditation (governed two types of meditations, which are tranquility meditation, and insight meditation) and soothing humor affect em- 
ployee's stress positively. Gura (2002) suggested practice of yoga and meditation at workplace, as it is convenient and practical as an antidote to relieve tension. Complementary therapies usage is initiated by various reasons, such as, recommendation by friends and family, maintenance for general health, to treat health problems, to relieve stress, natural healer, safe, greater control over health decisions, dissatisfaction with conventional medicine and for holistic orientation (Koh, Ng, \& Teo, 2004). People are more prone to use complementary therapies in managing anxiety, depression and other common psychological disorders (Wilson, White, \& Hamilton, 2013). Davidson, Geoghegan, Mclaughlin, and Woodward (2005) also claimed that complementary therapy act universally as supportive treatment on relaxation and stress reduction. On the contrary, the Chinese people use complementary therapy to nurture internal organ and maintain a holistic balance as the practices are already embedded in their culture (Watt, Gulati, Shaw, Sung, Dix, Poureslami, \& Klassen, 2012). Thus, Park (2013) concluded that complementary therapy can be exceptionally useful in mental health issues in conditions whereby psychological stress is vital. On the other hand. in Malaysia, there is an increased interest towards complementary therapy as shown by the establishment of Traditional and Complementary Medicine Division in Ministry of Health, availability of courses at Universities and colleges, and availability of integrated public hospitals that practiced complementary therapy (Abuduli et al., 2011).

\section{METHODOLOGY}

Qualitative methodology was used in investigating complementary therapy practices in the workplace. The location of the study was in Penang, since it is one of the places where complementary therapy practices are abundant. The population of this study was the community member of a group called Penang Holistic Health who practice various complementary therapies, such as, yoga, Qi gong, and reiki. There were five informants where purposive sampling was used as they are likely to generate useful data for the research. The qualitative data were analyzed using content analysis. All of the informants were selected based on two characteristics; 1) must practice complementary therapy, and 2) have experience in dealing with patients who experience job related stress. Table 1 shows the details of the 5 informants. Some of the questions were answered by the informants using English and some

Table 1: Informants' Details

\begin{tabular}{|c|c|c|c|c|c|}
\hline Respondent & 1 & 2 & 3 & 4 & 5 \\
\hline Age & 49 & 53 & 60 & 51 & 32 \\
\hline Gender & Female & Male & Male & Female & Female \\
\hline Location & Penang & Penang & Penang & Penang & Penang \\
\hline Years of Practice & 5 & 5 & 8 & 5 & 3 \\
\hline Ethnicity & Malay & Malay & Chinese & English & Greeks \\
\hline Type of Practice & $\begin{array}{l}\text { - Islamic Medi- } \\
\text { cal practice } \\
\text { (Ruqyah) } \\
\text { - Deep breath- } \\
\text { ing }\end{array}$ & $\begin{array}{l}\text { - Islamic } \\
\text { Medical } \\
\text { practice } \\
\text { (Ruqyah) }\end{array}$ & - Qigong & $\begin{array}{l}\text { - Yoga } \\
\text { - Reflexol- } \\
\text { ogy }\end{array}$ & $\begin{array}{l}\text { - Yoga } \\
\text { - Aromath- } \\
\text { eraphy } \\
\text { - Reflexol- } \\
\text { ogy } \\
\text { - Massage } \\
\text { - Reiki }\end{array}$ \\
\hline
\end{tabular}


were answered using the Malay language.

\section{FINDINGS AND DISCUSSION}

The study was carried out to answer three research questions: 1) what are the perceptions towards the use of complementary therapy?;2) what are the types of complementary therapies that can be practice by employees to reduce stress?; and 3) what are the effects of complementary therapies on occupational stress?

\section{Perceptions towards the use of comple- mentary therapy}

The first objective was to gain an understanding and insight of complementary therapy. Four themes were identified which were complementary therapy as a holistic treatment, natural way of healing, the person as its own healer, and the benefits and effectiveness of complementary therapy compared to medical treatment. Figure 1 illustrates the perceptions about the usage of complementary therapy and their preference between complementary therapies and conventional treatment.

\section{As a holistic treatment}

Holistic treatment is dealing or treating a person as a whole. Most of the informants claimed that complementary therapies serve as a treatment that heals or improves a person's health as a whole, including the aspects of physical, spiritual, emotional and mental of a person.

Informant 1:

"In my opinion, medical practices emphasizes only on the biological health of a person. They seem to neglect other important aspects of a human being. Therefore complementary therapies are practiced to improve the human's mental, emotional and spiritual health. It is hoped that the complementary therapies will result in a more holistically healthy human being."

Informant 4:

"Many of these therapies have come from hundreds if not thousands of years of wellgrounded knowledge and experience from India and China, for example, and have healed numerous people from diseases of varying nature, not just physical illnesses, but also emotional, mental and energetic imbalances. The benefits of yoga range from a simple short term benefit of feeling destressed and relaxed to healing external and internal illnesses as well as ultimately leading one to spiritual progress."

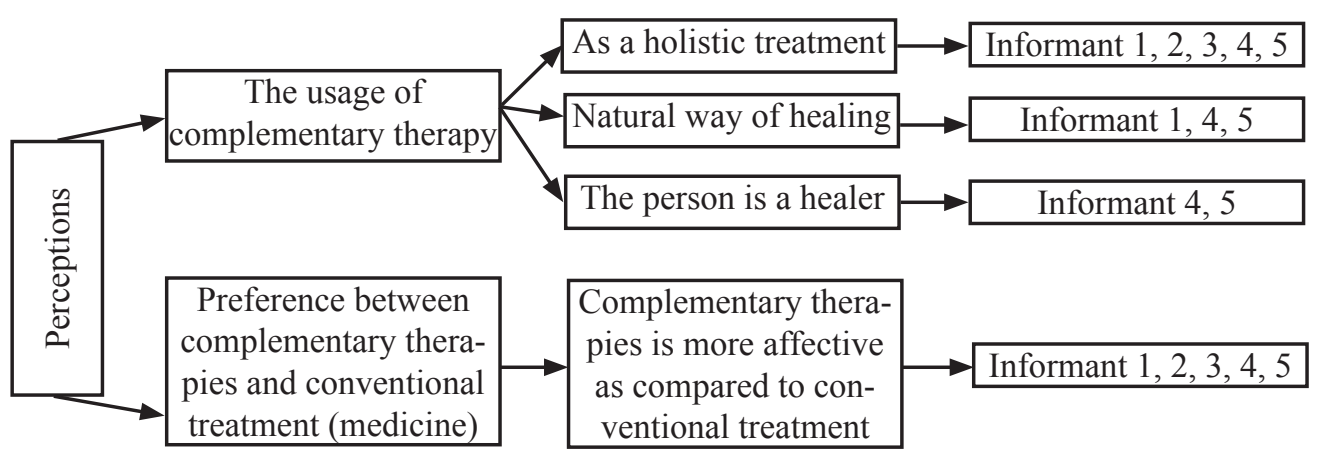

Figure 1: Perceptions on the use of complementary therapy 
Informant 5:

"With using complementary therapies we are able to reconnect to our own inner strength and recharge our inner batteries. Here complementary should be kind of must to keep your immune system up and gain more power back."

Meanwhile, Informant 2 also said that Islamic medical practices often use Quranic verses which indirectly makes a person more attached to the creator. This showed that there is evidence that the therapy enables a person to achieve spirituality as the practices are more holistic and spiritual because it involves religious ritual. Moreover, informant 3 also claimed that complementary therapy is based on the holism of man and nature.

Informant 2:

"Contohnya perubatan Islam banyak menggunakan ayat Quran."

"Rawatan perubatan Islam banyak mendekatkan kita kepada tuhan kerana menggunakan ayat Quran."

Informant 3:

"Generally speaking complementary therapy is founded on the holism of man and nature."

These findings are useful as it shows that complementary therapy does not just improve person in one aspect but it treats a person as a whole. An employee who has a balance in physical, mental, emotional and spiritual aspect is less likely to experience stress related workplace.
Complementary therapy governs a natural way of healing as the healing process itself is generated through the practices from one's own body. Complementary therapy is exclusive of chemical- oriented external healers but instead commonly used natural resources, such as, herbs, positive state of mind and energy. Most of the informants highlighted the statement of complementary therapy as a natural healer compared to medical treatment that uses prescribed medicine.

Informant 5:

"The difference between conventional treatments is that complementary therapy hardly has any side effect. It is simple as natural way of healing."

"Personally I always try to let my body heal in its most natural way before I ever grab a tablet. Like I said, the body is the mirror of our inner soul. With taking tablets it's not curing the root, it just narcotizing it."

Informant 1:

"Complementary therapies activities do not make use of drugs to enhance a human's health. The therapies vary from some form of exercises, consumption of natural herbs, application of aromatherapy to religious ritual."

Informant 4:

"Complementary therapy from the point of view that they are less invasive and not prescriptive, offer more 
natural ways to treating ailments. This is very different from mainstream medical practices which are treatment based and often see the patient as sick and unable to help him or herself. So obviously, complementary therapy is very different from common medical practices which are often medicine and treatment based rather than empowering and preventive."

"They are independent healing therapies in their own right and can help a person heal fully is he or she uses any one or a combination of so called "complementary therapies" without ever needing mainstream medical treatment."

\section{The person as a healer}

One of the most significant characteristics of complementary therapy is that the person himself or herself acts as healer for his or her own self. Throughout the process, the therapies are to be conducted and dependent on the person. Some of the therapies may need an instructor to guide them throughout the process but the practices require participation and effort from oneself. Two of the informants, i.e., informant 4 and informant 5 highlighted the concept of the person as a healer.

\section{Informant 4:}

"Complementary therapy is more empowering as they are driven and practiced by the person herself rather than relying on a doctor or an external healer. The basic prem- ise behind complementary therapy is that (you are your own healer), that the body has the intelligence to heal itself. If you trust in it and know how to work with your body, mind and emotional states."

"I have personally been able to heal and manage my severe lower back pains over the past 20 years by using a combination of complementary therapies without resorting to medical treatment which would have been to undergo a surgery."

Informant 5:

"You do nothing else than reactivating your body's own healing powers which can be very useful if you are going through a rough patch like chemo where you have a really weak immune system and react really sensitive to everything around you."

"I personally think that sickness is not appearing without a reason. Health issues just show us that there is something out of balance. On the other hand though, I believe that our body has the ability to heal itself."

"People have to start taking responsibility for their own bodies and thinking about reasons why they maybe getting one or the other health issue."

\section{More effective compared to convention- al treatment}

The benefits and effectiveness of comple- 
mentary therapies could be the rationale of why complementary therapy is chosen over other therapies. The benefits may vary from cost effective, safe to use, easy to conduct to more empowering compared to other therapies. All the respondents agree that complementary therapy is very effective and bring many benefits.

Informant 1:

"In my opinion, anyone can attempt complementary therapy because they are easy to practice with low risk of negative effect and cheap. In fact, they complement the medical treatment undergone by a person to improve his or her health."

Informant 2:

"Rawatan secara Islam lebih berkesan daripada perubatan moden dan kosnya lebih murah."

Informant 3:

"They keep me healthy."

Informant 4:

"I think complementary therapies are beneficial in their own right and not just complements to the mainstream medical practice. "Complementary therapy when properly practiced by a well-trained practitioner can sometimes heal illnesses and states of minds that mainstream medical practice may not be able to heal. So they can be more powerful and should be regarded with much more value they are."
Informant 5:

"There is medicine for nearly every sickness today at least for lots of them, but they have side effects as well and with those kinds of therapies we are able to weaken those effects and make the healing smoother and also sometimes faster. The difference to conventional medicine is that complementary therapy hardly has any side effects."

Koh et al. (2004) conducted a survey on the knowledge, attitude, and usage of alternative and complementary therapy in Singapore. As the survey population is in Singapore, the population of the study possibly has the same characteristics as the population of this study. The study reported that the reason of using alternative and complementary therapy is because of recommendation by friends and family $(70.6 \%)$, for maintenance of general health $(59.5 \%)$, to treat health problems (56.8\%), to relieve stress $(30.1 \%)$, natural and therefore safer $(17.6 \%)$, greater control over healthcare decisions $(14.8 \%)$, dissatisfaction with conventional medicine $(13.8 \%)$, and $(12.1 \%)$ on holistic orientation. From the findings of this study on objective 1, it can be reported that all of the informants are positive on the use of complementary therapy. Moreover, it can be assumed that the there is a positive attitude towards complementary therapy because of the nature of complementary therapy itself. The results have shown that complementary therapy is more beneficial and effective, act as a holistic treatment, the person as a healer, and a natural way of healing are the factors that triggers the use of complementary therapy. Thus, the findings from the study conducted by Koh et al. (2004) and the persent study are similar 
in terms of the basis of usage. Both studies have shown an evidence that the characteristics of complementary therapy which are natural, holistic, ability to relieve stress and greater control over healthcare decisions are the factors that triggers the usage of complementary therapy. Additionally, as complementary therapy, it is easy to be practiced by anyone. These practices can be easily implemented by the organization as part of their activities in managing employee's job stress. Besides, the benefits of practicing complementary therapy are innumerable and hardly cause destruction.

\section{Complementary therapies that can be practiced by employees to reduce stress}

The informants were asked to explain further on what complementary therapies do they practiced and how the current complementary therapy benefits them. The second question is intended to gain a rich data on how these practices are beneficial in reducing stress. Complementary therapy is defined differently by several parties. Complementary therapy in Malaysia has a convergence of three Asian cultures which are Malay, Indian, and Chinese (Merican, 2012). Consequently, practices that are influenced by a particular culture are referred as traditional practices (Ministry of Health Malaysia, 2011). Therefore, the themes that were developed as shown in Figure 2 results from the subdivision made by Traditional and Complementary Medicine Division of Ministry of Health Malaysia (2014), which are Islamic medical practices, traditional Indian practices, traditional Chinese practices, and complementary medicine.

\section{Islamic medical practices}

Informant 1 and Informant 2 use Islamic medical practices through the practice of Ruqyah which is the use of Quran recitation and praises ( $\mathrm{Zikr}$ ). Through the practice of Ruqyah and Zikr, both informants claimed that they make them feel at peace including healing physical ailments. Besides that, Informant 2 also emphasized that recitation of Quranic verses provide a mental, emotional, and spiritual healing.

Informant 2:

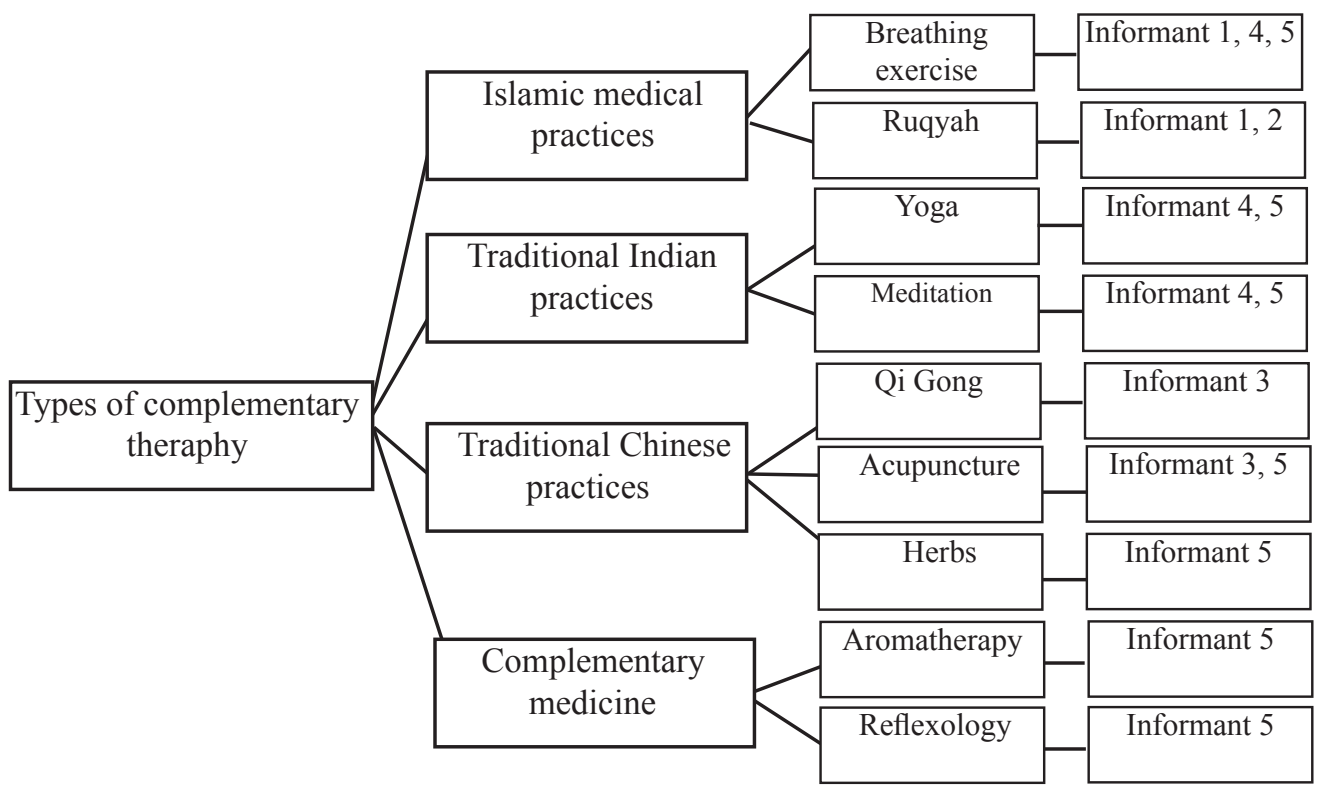

Figure 2: Types of complementary therapy 


\begin{abstract}
Nur Aishah Nor Hashim, Floriana Lendai ak Michael Mulok, and Helmi Sumilan
"Rawatan menggu-

nakan bacaan ayat Quran dan

air untuk pesakit minum."

"Perubatan yang

technique and Islamic medical treatment make me feel at peace even though I face a lot of problems."
\end{abstract}

menggunakan ayat Quran

dan berzikir menyebabkan

hati kita akan tenang disamp-

ing dapat menyembuhkan pe-

nyakit."

Informant 1:

"To me, Quranic

verses give a human being $a$

mental, emotional and spiri-

tual healing which seems to

be absent in medical prac-

tices."

Furthermore, Informant 2 also currently practices a combination of breathing technique and Islamic medical practices which involve taking a deep breath while reciting Quranic verses. She also claimed that through the years of practicing, it helps the most particularly in reducing stress by making her feel at peace even though at times of confronting a problem.

Informant 1 :

"At present, I am practicing a combination of breathing technique and Islamic medical treatment. The breathing technique involves deep breathing while reciting Quranic verses silently when holding breath for a few seconds. It has to be done a few times a day."

"I have been practicing these therapies for years and I feel that they help to reduce stress. I feel that the combination of breathing

\section{Traditional Indian practices}

Yoga is often associated with meditation. Thus, two of the informants, that is Informant 4 and Informant 5 combined the use meditation while practicing yoga.

Informant 4:

"Currently I teach

yoga and practice a little

meditation."

Informant 5:

"I daily do my own yoga practice and the most important is to meditate!"

On top of that, Informant 4 also explained in detail how the therapies that she conducted bring numerous benefits. The benefits are it can be easily practiced by anyone even to people with low energy level, people with physical injuries or generally physically weak as yoga is a gentle way to exercise the physical body. It supplies oxygen to the whole body through bloodstream which consequently helps to clear the mind, make one feels relaxed, clear and focused. Informant 4 also shared her personal experience of finding yoga being useful when she is highly stressed and depressed. Meanwhile, she also shared that her years of experience in practicing yoga make her feels more content, happier, living healthier, becoming more patient and more positive.

Informant 4:

"I have found yoga

very helpful in several ways. 
Nur Aishah Nor Hashim, Floriana Lendai ak Michael Mulok, and Helmi Sumilan

It is a gentle yet powerful way to exercise the physical body, especially if one has injuries or is generally physically weak. It brings in a lot more oxygen into the body, blood stream as well as the various organs and nourishes them. It helps to clear the mind from mental clutter so that one is more relaxed yet clear and focused after the practice. I found yoga the most useful during my years of being highly stressed and somewhat depressed."

Informant 5:

"Since I am practicing yoga for 7 years, I feel more content, happier with what I have right now instead of grasping for things I haven't. I started living healthier in each area of my life, I started looking at things differently, being more patient and more positive."

Thus, the outcomes of practicing yoga and meditation have showed how they are functional in maintaining employee's mental health at work. The findings can also be supported by a study made by Petchsawanga and Duchon (2012) on spirituality at work. The research used meditation training as a technique on implementing spirituality at work, whereby the study found that spirituality at work positively affects organizational outcomes in terms of job performance.

\section{Traditional Chinese practices}

Among the informants of the research only two of the informants are involved in Chinese related complementary therapy. Informant 3 practices Qigong therapy which includes short and distance healing. The healing process involved the transfer of energy to the patient who is having job related stress. In the meantime, Informant 5 uses herbal drops when she is having emotional problem and enjoy going for acupuncture to keep her yin and yang balanced. According to informant 5, yin covers the aspect of meditation and relaxation while yang covers the aspect of physical movement.

\section{Informant 3:}

$$
\text { "As an industrial }
$$
expert in Qigong therapy, I provide local and distance healing for patients who have job or family related stress. The services are very popular, a sign that many found the services helpful!"

Informant 5:

"I used herbal drops

by Dr. Bach when Ifeel emotionally out of place. I also love to go for acupuncture from time to time to keep my yin (meditation, relaxation) and yang (sports, activity) balance."

\section{Complementary medicine}

Informant 5 mentions that she also practices aromatherapy and reflexology. Aromatherapy governs the use of essential oils which is used to create a calming effect which is often made up of natural resources like herbs. Reflexology is the practices 
Nur Aishah Nor Hashim, Floriana Lendai ak Michael Mulok, and Helmi Sumilan

that focus on points that is believed to mark or relate to a particular organ.

Informant 5:

"I have different

habits like using aromatherapy and working on reflexology points (doterra essential oils, young living)."

"I am trained to do complementary therapies such as reflexology. Nowadays, there are so many different activities which can additionally help to balance or even heal the body better, like aromatherapy."

There are several methods suggested by previous studies on the issues of managing occupational stress. Based on this study, it is found that breathing exercises, Ruqyah, yoga, meditation, Qi gong, acupuncture, herbs, aromatherapy and reflexology are very useful as a workplace stress management practice. A study conducted by Othman and Sipon (2012) claimed that the act of worshipping God can be taken into account as meditation, whereby it can lower down high blood pressure, reduce anxiety, and release stress. This is also supported by Hill and Butter (1995) that religious beliefs influence the degree of a person's stress and the ability of coping with the stress (as cited in Othman \& Sipon, 2012). Furthermore, Cashwell and Young (2011) are also of the opinion that religious values benefits a person general wellness positively, and play a significant role is when one's is facing a crisis. Meanwhile, Antai-Otong (2001) articulated that religious renewal is an integral part of stress management as it makes a person to be clear in purpose, have a sense of hope, and meaning in life. Othman and Sipon (2012) are in opinion that these activities provide a reprieve from occupational stress which supported the second objective of this study that these practices can be practiced by employees as a stress management practice. On the other hand, yoga is often associated with stress management practice. Numerous studies, such as, Milligan (2006) constructed yoga for stress management program which aimed to enhance relaxation skills, improve focus attention, reduce anxiety, reduce depression and improve overall wellness. Moreover, Bock, Fava, Gaskins, Morrow, Williams, Jennings, Becker, Tremont, and Marcus (2012) through their study of using yoga as complementary treatment for smoking cessation has showed that yoga contains a number of components that helps in stress reduction, as well as, yoga postures have proven to improve moods and well-being. The findings for this study can also be supported by the research done by Deshpande (2012) which highlighted on yoga, meditation and soothing humor has a positive effect on the employees who were suffering from workplace stress. Gura (2002) also suggested that it is convenient and practical to be introduced to employees as an antidote to relieve tension. The study also suggested that breathing and postural techniques can be carried out quietly and unconstructively during working hours. Thus, it can be assume that the findings from this study are consistent with the previous studies that yoga and meditation are very functional to the issue of occupational stress.

The findings from this study have showed how the practice of Qigong, acupuncture and use of herbs are effective. However the study failed to explain further how these practices helps to reduce stress. This study is different from the study conducted by Chow (2011) that studied on the effects of Qigong on reducing 
stress, anxiety and enhancing body-mind wellbeing. Chow's study has demonstrated that after a period of Qigong practice, the participants experienced a better mood states using DASS-S (stress scale) as an indicator for decreases in stress, decreases in anxiety DASS-A (anxiety scale), and decreases in depression DASS-D (depression scale). Hence, it can be concluded that these practices help in mood augmentation, particularly in reducing stress, anxiety and improving quality of life.

\section{Effects of complementary therapies on occupational stress}

There were two sub questions asked during the interview session. The first question was to discover how complementary therapies benefit the person itself. The second question was to inquire how complementary therapies affect occupational stress.

Figure 3 shows how complementary therapy helps in reducing occupational stress. Based on the interview conducted, all of the informants were in full agreement that complementary therapy does help in reducing occupational stress. However, in order to gain an in depth understanding, the informants were asked to explain further on how complementary therapy help in reducing occupational stress. The data obtained was divided into three aspects, which are mental effect, emotional effect and physical effect.

\section{Mental effect}

Complementary therapy can be beneficial in many aspects. Most of the informants claimed that complementary therapy helps in reducing stress because these practices lead them to be more positive. This positive state of mind is useful when they are confronting problems and helps them view thing positively, which consequently reduced their stress from workplace. Informant 1,4 , and 5 explained that complementary therapy helps a person to move to a positive state of mind. In addition, Informant 4 also added that these practices help a person to stay focus and create a calming effect.

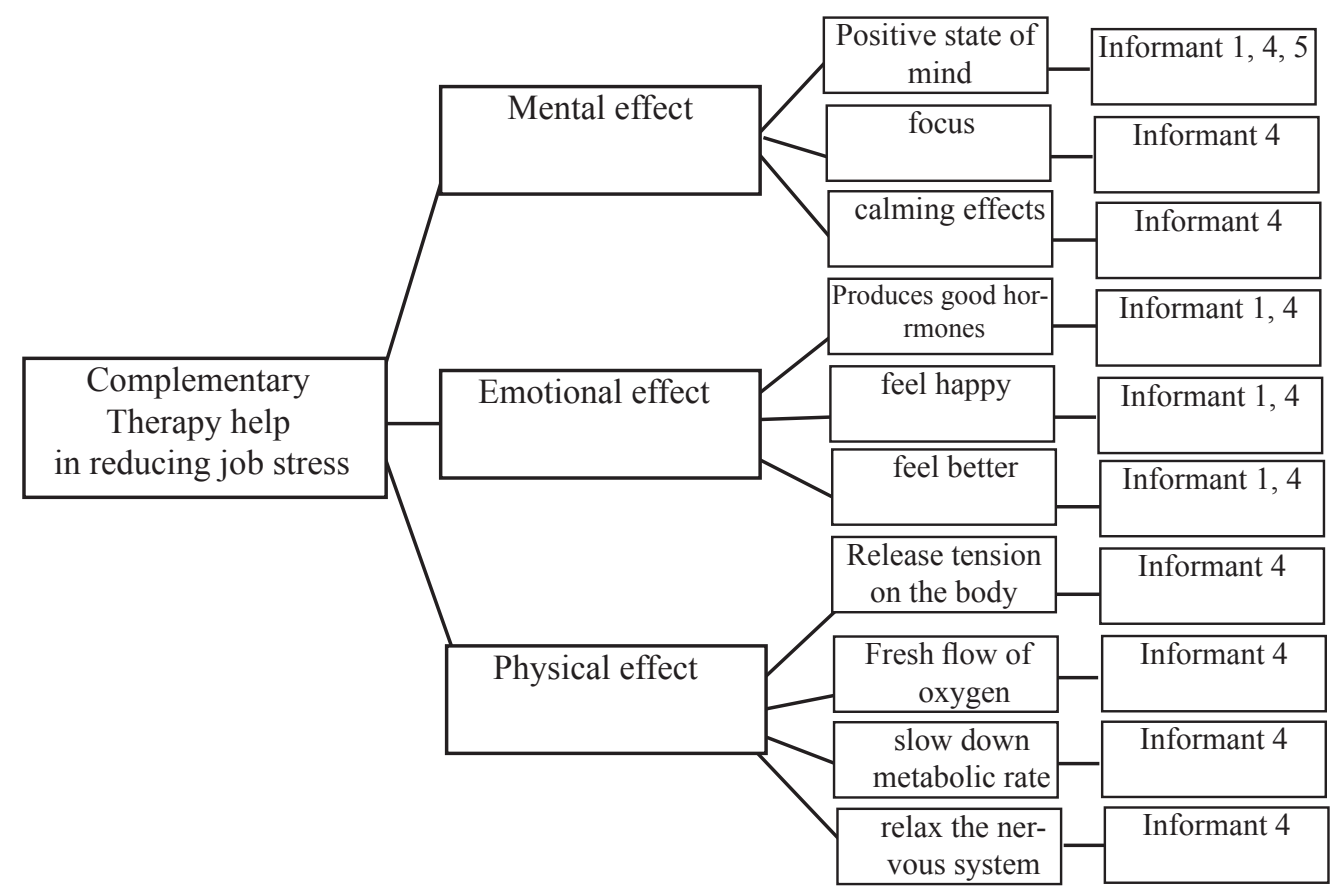

Figure 3: Complementary therapy helps in reducing job stress 
Nur Aishah Nor Hashim, Floriana Lendai ak Michael Mulok, and Helmi Sumilan

Informant 1:

"These therapies

help a person to be positive mentally."

Informant 4:

"Meditative part

of yoga helps to focus and reframe the mind into more positive states of being."

"Different kinds of breathing exercises are also used to create calming effects."

Informant 5:

"Alternative therapies help us to stay in the present moment, to prioritizes better."

\section{Emotional effect}

Complementary therapy affects the practitioner emotionally as most of the practices involved in the production of good hormones which are endorphins and serotonins. These good hormones play a role as an uplifting effect which makes a person to feel better and happy as mentioned by Informant 1 and 4 . On top of that, Informant 4 mentioned the emotional effect of feeling good and happy help in reducing job related stress.

Informant 1:

"When the body

and soul are at peace and experience tranquility, automatically the body produces masses of feel good hormones, namely, endorphins and serotonins. These hormones are believed to make one feels happy and positive."
Informant 4:

"It has an uplifting effect, and later I learnt that this was the increased of endorphin, a happy hormone effect."

"I have quite a few students that are so committed to yoga precisely because they feel so much better after class. These are classes that are held in the evening right after work."

\section{Physical effect}

A stressful person often feel a tension on their shoulders, neck and back muscles. Thus, Informant 4 claimed that physical part of yoga releases the tension on the shoulders, neck and back muscles. Furthermore, Informant 4 also mentioned that practices like breathing exercises are used to slow down metabolic rate, relax the nervous system, and produce a fresh flow of oxygen. The fresh flow of oxygen will nourished the organs, cells, and muscles.

Informant 4:

"Physical part of yoga helps to release tension often in the shoulders, neck and back muscles."

"Pranayama, which is a breathing exercise, help to bring fresh flow of oxygen into the blood stream to nourish organs and cells, as well as, muscles so that your entire physical body feels like it has been nourished." "Different kinds of breathing are also used to slow down metabolic rate and relax the nervous system." 
The study found that complementary therapy affects the informants physically, mentally and emotionally. Mentally, the informants informed that complementary therapy gives them a calming effect, a sense of focus and a change towards positive state of mind. This is consistent with the qualitative findings of the study made by Davidson et al. (2005). Their study supported the view that complementary therapy was almost universally acting as a supportive treatment on relaxation and stress reduction. Other findings from the current study are that complementary therapies can produce physical effect too as one of the informant claimed that breathing exercises can nourishes organs and cells of the body, which consequently makes the body having a higher content of oxygen and reduce the risk of having cancer. A study about the perceptions about complementary therapy use among Chinese immigrant parents on child with cancer supported the findings of the study that complementary therapies are used to nurture the internal organs and maintain a holistic balance of the body (Watt et al., 2012). This is similar to the concept explained by Informant 5 on keeping balance between the ying and yang. Also, this is supported by the statement made by Informant 4 that high oxygen content helps to nourish the body.

\section{CONCLUSION}

The findings of this study highlighted the benefits of complementary therapy associated with physical, emotional and mental health of a person. Occupational stress issue has always been a concern in the area of occupational safety and health. However, lack of solution and prevention are being discussed in this issue. Hence, the study suggested complementary therapy as an alternative solution to the issue. Also this study provides a contribution to the understanding of complementary therapy. Organizations and leaders can use complementary therapy as an integral part of strategic initiatives. As complementary therapy is integrated as part of strategic initiatives, this could produce beneficial outcomes, such as, improved productivity, changed in positive attitude towards work, reduces burnout and turnover cases, improves employee's focus, and improves employee's health. These practices also could change organizational culture to that of a healthy organization climate, which indirectly leads to organization longevity.

\section{REFERENCES}

Abuduli, M., Ezat, S., \& Aljunid, S. (2011). Role of traditional and complementary medicine in universal coverage. Malaysian Journal of Public Health Medicine, 11(2), 1-5.

Antai-Otong, D. (2001). Creative stress management technique for selfrenewal. Dermatology Nursing 13 (1), 31-39.

Bock, C. B., Fava, L. J., Gaskins, R., Morrow, M. K., Williams, M. D., Jennings, E., Becker, M. B., Tremont, G., \& Marcus, H. B. (2012). Yoga as a complementary treatment for smoking cessation in women. Journal of Women's Health, 21(2), 240248.

Cashwell, C. S., \& Young, J. S. (2011). Integrating spirituality and religion into counselling. A guide to competent practice. (2nd ed.). Alexandria, VA: Stevenson Avenue.

Choi, S. L., Tan, O. K., Teoh, A. P., \& Muthuveloo, R. (2014). Investigation on the impact of job stressors on nurses in Malaysia. Asian Social Science, 10(4), 67-77.

Ching, M. S., Zakaria, A. Z., Paimin, F., \& Jalalian, M. (2013). Comple- 
Nur Aishah Nor Hashim, Floriana Lendai ak Michael Mulok, and Helmi Sumilan

mentary alternative medicine use among patients with type 2 diabetes mellitus in the primary care setting: A cross sectional study. $B M C$ Complementary and Alternative Medicine, 13(148), 1-7.

Chow, W. Y. (2011). The effects of qigong on reducing stress, anxiety and enhancing body-mind wellbeing. (Unpublished doctoral dissertation) The Hong Kong Polytechnic University, HK.

Davidson, R., Geoghegan, L., Mclaughlin, L., \& Woodward, R. (2005). Psychological characteristics of patients who use complementary therapies. Psycho-oncology, 14(3), 187-195.

Deshpande. C. R. (2012). A healthy way to handle work place stress through yoga, meditation, and soothing humour. International Journal of Environmental Sciences, 2(4), 2143 2154.

European Agency for Safety and Health at work renews attention on managing work-related stress [Pamphlet]. (2014). N.p. American Society of Safety Engineers.

Gura, T. S. (2002). Yoga for stress reduction and injury prevention at work. Work. 19, 3-7,

Idris, M. I., Dollard, F. M., \& Winefield, H. A. (2010). Lay theory explanations of occupational stress: the Malaysian context. Cross Cultural Management: An International Journal, 17(2), 135-153.

Jamal, M. (2011). Job stress, job performance and organizational commitment in a multinational company: an empirical study in two countries. International Journal of Business and Social Science, 2(20), 20-29.

Johnson, S., Cooper, C., Cartwright, S., Donald, I., Taylor, P., \& Millet, C.
(2005). The experience of workrelated stress across occupations. Journal of Managerial Psychology, 20(2) 178-187.

Koh, L. H., Ng, L. H., \& Teo, H. H. (2004). A survey on knowledge, attitudes and usage of complementary and alternative medicine in Singapore. Asia Pacific Biotech, 8(23), 12661270.

Manshor, A., Fontaine, R., \& Chong, S. (2003). Occupational stress among managers: A Malaysian survey. Journal of Managerial Psychology, 18(6), 622-628.

Merican, I. (2002). Traditional/ complementary medicine: The way ahead. Ministry of Health: Institute of Medical Research, 57(3).

Milligan, C. (2006). Yoga for stress management programme as a complementary alternative counselling resource in a university counselling center. Journal of College Counselling, 9.

Ministry of Health Malaysia. (2011). Traditional and complementary medicine programme in Malaysia. Retrieved from http://tcm.moh.gov. my.

Moustaka, E., \& Constantinidis., C. T. (2010). Sources and effects of work-related stress in nursing. Health Science Journal, 4(4), 210216.

National Centre for Complementary and Alternative Medicine. (2009). Transcendental meditation helps young adults cope with stress. Retrieved from http://nccam.nih.gov.

Othman, K., \& Sipon, S. (2012). Researching solution based on Islamic views and practice in managing financial and work place stress. International Journal of Academic Research in Business and Social Sciences, 2 
(8), 239-252.

Park, C. (2013). Mind-body interventions: current status and considerations for integration into clinical health psychology. Journal of Clinical Psychology, 69(1), 45-63.

Petchsawanga, P., \& Duchon, D. (2012). Workplace spirituality, meditation and work performance. Management Department Faculty Publications, 92.

Raja, L. R. G., Oranye, N. O., Ho, S. E., Zuraida, J., \& Zulkifli, S. Z. (2013). Complementary and alternative medicine use among breast cancer patients in a tertiary hospital in Malaysia. Malaysian Journal of Public Health Medicine, 13(1), 11-19.

Regus. (2013, November 22). 70\% Malaysian workers see increase in stressrelated illnesses. The Star Online. Retrieved from http://www.thestar. com.my.

Safaria, T., Ahmad, O., \& Wahab, N. A. M. (2008). Gender, academic rank, employment status, university type, and job stress among university academic staff: a comparison between Malaysia and Indonesia context. International Journal of Humanities and Social Science, l(18), 250-261.

Traditional and Complementary Medicine Division of Ministry of Health. (2014). Traditional and complementary practices. Retrieved from http://tcm.mog.gov.my.

Watt, L., Gulati, S., Shaw, T. N., Sung, L., Dix, D., Poureslami, I., \& Klassen, F. A. (2012). Perceptions about complementary and alternative medicine among Chinese immigrant parents of children with cancer. Support Care Cancer, 20(2), 253-260.

Wilson, M. A. L., White, M. K., \& Ham- ilton, K. (2013). Predicting psychologists' intentions to integrate complementary and alternative therapies into their place. Australian Psychologist, 48(2), 149-158.

World Health Organization, (2005). Mental health policies and programmes in the workplace. Geneva. 